\title{
The anti-nociceptive agent SBFI-26 binds to anandamide transporters FABP5 and FABP7 at two different sites
}

\author{
Hao-Chi Hsu', Simon Tong ${ }^{2}$, Yuchen Zhou ${ }^{3}$, Matthew Elmes ${ }^{4}$, Su Yan², Martin Kaczocha ${ }^{4,5}$,

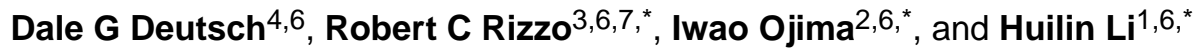 \\ ${ }^{1}$ Cryo-EM Structural Biology Laboratory, Van Andel Research Institute, Grand Rapids, MI 49503 \\ ${ }^{2}$ Department of Chemistry, Stony Brook University, Stony Brook, NY 11794 \\ ${ }^{3}$ Department of Applied Mathematics and Statistics, Stony Brook University, Stony Brook, NY \\ 11794 \\ ${ }^{4}$ Department of Biochemistry and Cell Biology, Stony Brook University, Stony Brook, NY 11794 \\ ${ }^{5}$ Department of Anesthesiology, Stony Brook University, Stony Brook, NY, 11794 \\ ${ }^{6}$ Institute of Chemical Biology and Drug Discovery, Stony Brook University, Stony Brook, NY \\ 11794 \\ ${ }^{7}$ Laufer Center for Physical \& Quantitative Biology, Stony Brook University, Stony Brook, NY \\ 11794
}

\section{Abstract}

Human FABP5 and FABP7 are intracellular endocannabinoid transporters. SBFI-26 is an atruxillic acid 1-naphthyl monoester that inhibits the activities of FABP5 and FABP7 and produces antinociceptive and anti-inflammatory effects in mice. The synthesis of SBFI-26 yields several stereoisomers, and it is not known how the inhibitor binds the transporters. Here we report cocrystal structures of SBFI-26 in complex with human FABP5 and FABP7 at a resolution of $2.2 \AA$ and $1.9 \AA$, respectively. We found that only $(S)$-SBFI-26 was present in the crystal structures. The inhibitor largely mimics the fatty acid binding pattern, but it also has several unique interactions. Notably, the FABP7 complex corroborates key aspects of the ligand binding pose at the canonical site previously predicted by virtual screening. In FABP5, SBFI-26 was unexpectedly found to bind at the substrate entry portal region in addition to binding at the canonical ligand-binding pocket. Our structural and binding energy analyses indicate that both $(R)$ and $(S)$ forms appear to bind the transporter equally well. We suggest that the $(S)$ enantiomer observed in the crystal structures may be a result of the crystallization process selectively incorporating the (S)-SBFI-26-FABP complexes into the growing lattice, or that the (S)-enantiomer may bind to the portal site more rapidly than to the canonical site, leading to an increased local concentration of the (S) enantiomer for binding to the canonical site. Our work reveals two binding poses of SBFI-26 in its target

*Corresponding author (H.L.), Address: Van Andel Research Institute, 333 Bostwick Ave., NE, Grand Rapids, MI 49503. Tel: 616-234-5306. Huilin.Li@vai.org. 'Corresponding author (R.R.), Address: Department of Applied Mathematics \& Statistics, Institute of Chemical Biology \& Drug Discovery, Laufer Center for Physical \& Quantitative Biology, Stony Brook University, Stony Brook NY, 11794-3600. rizzorc@ gmail.com. Corresponding author (I.O.), Address: Institute of Chemical Biology \& Drug Discovery, Chemistry Department, Stony Brook University, Stony Brook NY 11794-3400. iwao.ojima@stonybrook.edu. 
transporters. This knowledge will guide the development of more potent FABP inhibitors based upon the SBFI-26 scaffold.

\section{Table of Contents}

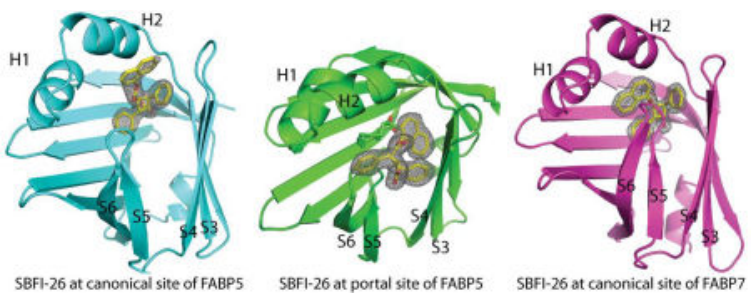

\section{Keywords}

Anandamide transporter; fatty acid binding proteins (FABP); anti-nociceptive agents; truxillic acids; structural biology; DOCK; footprint similarity; docking; SBFI-26

\section{INTRODUCTION}

The endocannabinoids such as anandamide (AEA), 2-arachidonoylglyerol (2-AG), and the related $N$-acylethanolamines (NAEs) are fatty acid neurotransmitters that activate cannabinoid receptors (CBs) in the brain and the immune system ${ }^{1}$. Tissue AEA levels are regulated by fatty acid binding protein (FABP)-mediated intracellular transport to the catalytic enzyme fatty acid amide hydrolase (FAAH) ${ }^{2,3}$. FABP5 and FABP7 are the intracellular transporters of AEA 4, 5 . Inhibition of FABPs reduces AEA inactivation in vitro and elevates AEA levels in vivo ${ }^{4,6-8}$. Thus, FABP5 and FABP7 are novel targets for modulating AEA levels and signaling pathways 9,10 .

FABPs are a family of intracellular lipid-binding proteins. FABPs reversibly bind hydrophobic ligands such as fatty acids and their acyl derivatives from the cell membrane and traffic them throughout various intracellular compartments. There are ten known FABP isoforms in humans that are expressed in many tissues and regulate many cellular processes, including lipid metabolism, inflammation, sleep, and neuronal signaling ${ }^{11-16}$. For example, FABP5 was first found in epidermal cells (and therefore is also called E-FABP), but the protein is found in many cell types including the brain. We recently found that FABP5 is also expressed in nociceptive dorsal root ganglia and the spinal cord, and inhibition of FABP5 exerts peripheral and supra-spinal analgesic effects ${ }^{17}$. FABP7 was first identified in brain and therefore is also called B-FABP. Although the sequence identity of FABP family members varies from $20 \%$ to $70 \%$, they share a similar tertiary structure that is essentially a water-filled ligand-binding pocket. This pocket comprises a $\beta$-barrel formed by ten antiparallel $\beta$-strands and an N-terminal helix-turn-helix (HTH) cap (Fig. 1A) ${ }^{5,18-21}$.

Interestingly, the structures of FABPs in apo form and in their ligand-bound complexes are usually similar ${ }^{9}$. Because the ligands are large and the space between the HTH cap and the $\beta$-barrel is too small for the ligands to freely diffuse through, a "portal hypothesis" has been proposed in which the portal, composed of a-helix H2 and two loops of the S3-S4 and S5- 
S6 strands, may open for the ligand's entrance into the deep substrate-binding pocket (Fig. 1A) ${ }^{18,22}$. However, how and the extent to which the portal region opens have not been well characterized ${ }^{23}$. It has also been unclear whether the portal region plays a role in ligand selection.

SBFI-26 is an a-truxillic acid 1-naphthyl monoester (Fig. 1B). As we reported earlier ${ }^{7,24}$, SBFI-26 was originally identified using a computational docking protocol (DOCK6 program) ${ }^{25}$ in which a previously published crystal structure ${ }^{26}$ of FABP7 in complex with a fatty acid was employed for a large-scale virtual screen. The screening protocol docked over 1 million purchasable compounds (ZINC database) ${ }^{27}$ to the fatty-acid-removed FABP7 structure ${ }^{24}$. Candidate ligands were prioritized for purchase and experimental testing was based on several criteria, including the use of footprint similarity scoring to identify compounds having similar interaction patterns as the cognate ligand ${ }^{28,29}$. SBFI-26 was synthesized as a mixture of both the $(S)$ and $(R)$ enantiomers ${ }^{24}$. It produced antinociceptive and anti-inflammatory effects in mice and inhibited the activities of FABP5 and FABP7 with $\mathrm{K}_{\mathrm{i}}$ values of $0.9 \mu \mathrm{M}$ and $0.4 \mu \mathrm{M}$, respectively 7,24 . The previous computational docking has suggested the $(R)$ enantiomer is a better ligand for FABP7, but the active form of SBFI-26 (and how it interacts with these FABPs) has yet to be experimentally determined. In this work, we found that only the $(S)$ enantiomer of SBFI-26 was present in the co-crystal structures with FABP5 and FABP7. Serendipitously, we captured SBFI-26 at the canonical substrate-binding site as well as at the substrate-entry portal site in FABP5. By a detailed computational energetic analysis, we found that the canonical sites of FABP5 and FABP7 could accommodate both enantiomers of SBFI-26 equally well.

\section{MATERIALS AND EXPERIMENTAL DETAILS}

\section{Chemical Synthesis of 1-Naphthyl a-Truxillate (SBFI-26)}

The synthesis of SBFI-26 followed the procedures reported previously ${ }^{7}$. Briefly, a-truxillic acid was prepared in 93-95\% yield by the modified literature method ${ }^{24}$ through irradiation of trans-cinnamic acid at $350 \mathrm{~nm}$ with a $280 \mathrm{~mW} / \mathrm{cm}^{2}$ light. Then, a-truxillic acid $(595 \mathrm{mg}$, $2.0 \mathrm{mmol}$ ) was reacted with thionyl chloride $(3 \mathrm{~mL})$ and one drop of dimethyl formamide (DMF) at reflux for $3 \mathrm{~h}$, followed by the removal of excess thionyl chloride and DMF in vacuo to give a-truxillic acid dichloride. The acid chloride thus obtained was reacted with 1naphthol (240 mg, $1.68 \mathrm{mmol})$ and pyridine $(0.5 \mathrm{~mL})$ in tetrahydrofuran (THF; $15 \mathrm{~mL}$ ) at reflux for $3 \mathrm{~h}$. The reaction was quenched with water $(2 \mathrm{~mL})$ and extracted with ethyl acetate $(15 \mathrm{~mL})$. The organic layer was dried over anhydrous $\mathrm{MgSO}_{4}$ and concentrated in vacuo. The crude product was purified by flashed column chromatography on silica gel (ethyl acetate/hexanes) to give SBFI-26 as white solid (390 mg, 55\%): m.p.: $195-196{ }^{\circ} \mathrm{C} ;{ }^{1} \mathrm{H}$ NMR $\left(500 \mathrm{MHz}, \mathrm{CDCl}_{3}\right) \delta 4.16(\mathrm{dd}, J=10.6,7.4 \mathrm{~Hz}, 1 \mathrm{H}), 4.40(\mathrm{dd}, J=10.6,7.4 \mathrm{~Hz}, 1 \mathrm{H}), 4.63-$ $4.69(\mathrm{~m}, 2 \mathrm{H}), 6.28(\mathrm{~d}, J=8.2 \mathrm{~Hz}, 1 \mathrm{H}), 7.12(\mathrm{~d}, J=8.2 \mathrm{~Hz}, 1 \mathrm{H}), 7.24(\mathrm{~d}, J=8.2 \mathrm{~Hz}, 1 \mathrm{H})$, 7.33-7.27 (m, 2 H), 7.38-7.46 (m, 8 H), 7.49-7.51 (m, 2 H), 7.63 (d, $J=8.2 \mathrm{~Hz}, 1 \mathrm{H}), 7.77$ (d, $J=8.2 \mathrm{~Hz}, 1 \mathrm{H}$ ); Mass (ES-API, negative mode) $\mathrm{m} / \mathrm{z}$ calculated for $\mathrm{C}_{28} \mathrm{H}_{21} \mathrm{O}_{4}[\mathrm{M}-1]^{-}$: 421.1, found 421.1 (negative mode); HRMS (TOF) m/e calculated for $\mathrm{C}_{28} \mathrm{H}_{22} \mathrm{O}_{4} \mathrm{H}^{+}$: 423.1589. Found: 423.1596 ( $\Delta=1.7 \mathrm{ppm})$. 


\section{Protein Expression and Purification}

Cloning and expression of FABP5 and FABP7 were described elsewhere ${ }^{24}$. Briefly, a pET28a vector consisting of human $F A B P 5$ or $F A B P 7$ gene was expressed in the BL21(DE3) E. coli strain. Cells were grown at $37^{\circ} \mathrm{C}$ to $\mathrm{OD}_{600}=0.5-0.6$ before being induced with $0.5 \mathrm{mM}$ Isopropyl $\beta$-D-1-thiogalactopyranoside. Both human FABP5 and FABP7 were expressed at $18{ }^{\circ} \mathrm{C}$ for $16 \mathrm{~h}$. Cells were harvested by centrifugation and were lysed by passing through a Microfluidizer cell disruptor in $10 \mathrm{mM}$ potassium phosphate $(\mathrm{pH}$ 8.0), $10 \mathrm{mM}$ imidazole, and $0.25 \mathrm{M} \mathrm{NaCl}$. The homogenates were clarified by spinning at $27,000 \times g$, and the supernatant was applied to a HiTrap-Ni column (GE Healthcare) preequilibrated with the lysis buffer. His-tagged proteins were eluted with a $10-300 \mathrm{mM}$ imidazole gradient in $10 \mathrm{mM}$ potassium phosphate $(\mathrm{pH} 8.0)$ and $0.25 \mathrm{M} \mathrm{NaCl}$. To remove the N-terminal His-tag, FABPs were incubated with thrombin overnight at $4{ }^{\circ} \mathrm{C}$ in $50 \mathrm{mM}$ Tris (pH 8.5) and $0.15 \mathrm{M} \mathrm{NaCl}$. After clearing the undigested His-FABPs by passing through HiTrap-Ni column, FABPs were applied to a Superdex 75 column $(16 \times 1000 \mathrm{~mm}$, GE Healthcare) equilibrated with $10 \mathrm{mM}$ Tris (pH 8.5), $1 \mathrm{mM}$ dithiothreitol, and $0.15 \mathrm{M} \mathrm{NaCl}$. Delipidation was performed by incubating FABPs with hydroxyalkoxypropyl-dextran (Sigma) for $1 \mathrm{~h}$ at $37^{\circ} \mathrm{C}$. The purified FABP5 and FABP7 were concentrated to $25 \mathrm{mg} / \mathrm{ml}$ and $50 \mathrm{mg} / \mathrm{ml}$, respectively.

\section{Co-crystallization and structure determination}

Before crystallization, FABP5 was incubated with SBFI-26 at room temperature for $30 \mathrm{~min}$ at a molar ratio of 1: 3 (protein: ligand). FABP5-SBFI-26 complex was crystallized at $293 \mathrm{~K}$ by the hanging-drop vapor diffusion method using $0.1 \mathrm{M}$ HEPES, $\mathrm{pH} 7.5,2 \%$ polyethylene glycol 400, and 2.1 M ammonium sulfate as precipitant. Diffraction data of FABP5-SBFI-26 were collected at the X6A beamline of National Synchrotron Light Source (NSLS), Brookhaven National Laboratory, and were processed with Mosflm software. The space group of FABP5-SBFI-26 crystal was P1 and the structure was solved by molecular replacement program PHASER using the apo-FABP5 structure (PDB ID 4LKP) as the initial search model. The FABP7-SBFI-26 complex was obtained by mixing FABP7 and SBFI-26 at a 1:2 molar ratio for $30 \mathrm{~min}$ at room temperature. The FABP7-SBFI-26 co-crystals were grown at $293 \mathrm{~K}$ by the sitting-drop vapor diffusion method using $0.1 \mathrm{M}$ Tris, $\mathrm{pH} 8.5,0.1 \mathrm{M}$ lithium sulfate, and 33\% polyethylene glycol 4000 as the mother liquor. Diffraction data of FABP7-SBFI-26 to resolution of $1.9 \AA$ were collected at Lilly Research Laboratories Collaborative Access Team (LRL-CAT) beamline of Advanced Photon Source (APS), Argonne National Laboratory, and were processed with Mosflm software. The space group of FABP7-SBFI-26 crystal was P21 and the structure was solved by molecular replacement program PHASER using previously solved FABP7 structure (PDB ID 1FDQ) as the initial search model. After building the corresponding inhibitor models in Coot ${ }^{30}$, the refinements were performed using Phenix-refine ${ }^{31}$; the statistics are provided in Table 1.

\section{Computational analysis}

Ligand RMSD values between predicted and experimental binding geometries were computed using the Hungarian algorithm ${ }^{32}$, as implemented into the program DOCK ${ }^{25}$, following alignment of the predicted FABP7- $(R)$-SBFI-26 structure (based on pdb code 
1FE3) with the new FABP7-(S)-SBFI-26 crystal structure, and the new FABP5-(S)-SBFI-26 crystal structure. The Chimera program ${ }^{33}$ MatchMaker feature was employed for the alignments (C-alpha backbone atoms). Per-residue interaction energy profiles (molecular footprints) and re-docking calculations were computed using DOCK.

Molecular dynamics (MD) simulation protocols, analysis, and free energy calculations followed that recently reported by Zhou et al. ${ }^{34}$ using the AMBER 16 suite of programs ${ }^{35}$. The module tleap was employed to prepare and assemble each system. Briefly, setups employed the ff99SB ${ }^{36}$ force field for the protein and GAFF ${ }^{37}$ force field for the SBFI-26 ligand which was augmented with AM1-BCC ${ }^{38}$ partial atomic charges. The TIP3P 39 explicit water model was used to solvate the system. The MD simulations (pmemd module) were carried out at $298.15 \mathrm{~K}$ under NPT conditions, with $120 \mathrm{~ns}$ of data collection after a nine-step minimization/equilibration schedule, during which positional restraints imposed on the ligand and protein were gradually decreased to relax the complex in an orderly manner. The data collection phase employed a weak restraint $\left(0.1 \mathrm{kcal} \mathrm{mol}^{-1} \AA^{-2}\right)$ on the protein backbone atoms and no restraints on SBFI-26. The MD trajectories were processed with the cpptraj module to gauge geometric stability through root mean square deviation (RMSD) analysis. Free energies of binding were estimated using the "single trajectory" MM-GBSA 40, 41 implicit solvent model using periodically saved snapshots taken from the explicit solvent simulations. Although $120 \mathrm{~ns}$ is not necessarily a long MD simulation, under conditions that employ a weak protein backbone restraint, as little as 2-20 ns appears to be sufficient to establish whether a predicted docked pose can be categorized as geometrically or energetically stable as previously discussed $34,42,43$.

\section{RESULTS}

\section{Structure determination of SBFI-26 in complex with human FABP5 or FABP7}

We expressed the human FABP5 and FABP7 in E. coli and purified the proteins to homogeneity. A standard delipidation protocol was used to remove the endogenous fatty acids in these proteins. We co-crystallized FABP5 or FABP7 in an excess amount of a racemic mixture of SBFI-26. The co-crystals of FABP5-SBFI-26 and FABP7-SBFI-26 diffracted to a resolution of $2.2 \AA$ and $1.9 \AA$, respectively. The statistics of the diffraction data and the structure refinement are listed in Table 1. We solved these structures by the molecular replacement method.

By examining the Fo-Fc and 2Fo-Fc maps (Fig. 2, Supplementary Fig.1), we found that SBFI-26 was clearly present in the co-crystallized structures with FABP5 and with FABP7. The FABP5-SBFI-26 complex was crystallized in the P1 space group. There were eight FABP5 molecules in the asymmetric unit: four proteins were found to each bind to an SBFI-26 at the canonical substrate binding pocket (Fig. 2A), and the remaining four proteins each bound to the inhibitor at a previous unobserved site at the substrate entry portal region (Fig. 2B). The four FABP5-SBFI-26 portal-site structures and the four canonical-site structures are very similar among themselves, with the average RMSD of $0.36 \AA$ and $0.55 \AA$, respectively. In FABP7, SBFI-26 resides in the canonical substrate-binding pocket (Fig. 2C). The electron density was detailed enough that we were able to unambiguously assign the SBFI-26 as the (S) enantiomer in all structures (Fig. 2A-C). We therefore conclude that only 
the (S) form, but not the (R) form, of SBFI-26 is able to bind FABP5 or FABP7 under our crystallization conditions.

\section{Conformational changes of FABP5 and FABP7 upon binding to SBFI-26}

The crystal structure of the human apo FABP5 was reported previously; its portal area is nearly closed ${ }^{44}$ (Fig. 3A, left). In our structure of SBFI-26 bound at the portal site of human FABP5, the S3-S4 loop moves outward by $5 \AA$, and the $\mathrm{H} 2$ and S3-S4 strands also move outward slightly (Fig. 3A, middle and right). These movements create enough space to accommodate the bulky naphthalene ring and the phenyl ring, enabling SBFI-26 to partially insert into the slightly open portal site. In this pose, the SBFI-26 carboxylate is still outside facing the solvent. To allow SBFI-26 to fully enter the ligand binding pocket and bind to the canonical site, the $\mathrm{H} 2$ and S3-S4 strands move further out, and the S5-S6 loop moves outward by as much as $8.0 \AA$ (Fig. 3B, left and middle). Interestingly, the side chains of Leu32 of helix H2, and Leu60 and Lys61 of S3-S4 also rotate outward, further increasing the portal size (Fig. 3B, right). Therefore, in FABP5, even when SBFI-26 has reached its canonical site, the portal remains wide open. This is very different from FABP7, in which the portal region is essentially closed when the SBFI-26 is bound to the canonical site (Fig. $3 \mathrm{C}$, left). The structure of the human FABP7 in the apo form is not known, but the structure of human FABP7 in complex with a fatty acid has been reported ${ }^{26}$. Compared with the FAbound FABP7, the $\mathrm{H} 2$ helix and the S3-S4 and S5-S6 loops move slightly outwards in the FABP7-SBFI-26 structure, creating a small gap for the side chain of Phe58 to swing inward and close the portal (Fig. 3C, middle and right).

It is unclear whether the closed portal configuration of FABP7 or the open port configuration of FABP5 represents the end state of substrate binding, because in both structures, SBFI-26 has fully entered the substrate pocket and is bound at the canonical site. It is possible that the portal region fluctuates in solution between the open and the closed forms while the ligand is bound at the canonical site. This scenario is supported by a previous NMR and deuterium exchange studies revealing the highly dynamic nature of these human FABP proteins at the portal and helical lid regions ${ }^{45}$. Interestingly, a previous work suggested that the interaction between Leu60 in the S3-S4 loop and Met35 in H2 specifies the ligand-bound active state of FABP5 ${ }^{44}$. Another work indicated that the inward-pointing orientation of the Phe57 side chain in the S3-S4 loop (equivalent of Phe58 in FABP7) is required for FABP4 to undergo a conformational change that results in the exposure of its nuclear localization signal to the solution ${ }^{46}$. These observations appear to reflect the fact that the portal region is highly dynamic and actively sampling multiple conformations.

\section{Interaction between SBFI-26 and the canonical sites of FABP5 and FABP7}

In FABPs, the native substrate fatty acids bind to and form salt bridges and hydrogen bonds (H-bonds) with two arginines and a tyrosine inside the canonical ligand binding sites. These residues are Arg109, $\operatorname{Arg} 129$, and Tyr 131 in FABP5, and $\operatorname{Arg} 107, \operatorname{Arg} 127$, and Tyr 129 in FABP7. In the canonical-site FABP5-SBFI-26 complex, SBFI-26 appears to mimic the native substrates, with its carboxylate forming a salt bridge with Arg129, an H-bond with Tyr131, and four H-bonds with Arg109 via an ordered water molecule (Fig. 4A). Similar interactions were also observed in the FABP7-SBFI-26 complex, in which the carboxyl 
group of SBFI-26 formed a salt bridge with Arg127 and a water-mediated network of hydrogen bonds was formed among the carboxyl group, Arg127, Tyr129, Arg 107, and Thr54 (Fig. 4B). Additionally, a water mediated four H-bonds among the backbone oxygens of Gly34 and Thr37, the NH group of Arg127, and the carbonyl oxygen of SBFI-26. These Hbonds are ligand-specific and are not observed in the fatty acid-bound FABPs. In FABP7, the hydrophobic residues Phe17, Met21, Leu24, Val26, Thr30, Pro 39, Phe58, Ala76, Phe105, Met116, and Leu118 formed hydrophobic interactions with the two phenyl rings and the naphthalene ring of SBFI-26 (Fig 4C). These hydrophobic portal residues also contribute to the binding of the native substrate fatty acids ${ }^{26}$.

\section{Structural comparison between the DOCK-predicted pose for SBFI-26 and the crystallographic pose}

Determination of the crystal structures of SBFI-26 in complex with either FABP7 or FABP5 afforded the opportunity to compare the original DOCK binding geometry (pose) reported previously 7,24 with those observed in the present work (Fig. 5). The theoretical and experimental poses of SBFI-26 with FABP7 show remarkable overlap and have a low heavyatom root-mean-square-deviation (RMSD) of $2.7 \AA$, despite the fact the DOCK prediction originally led to the identification of the $(R)$ enantiomer but the FABP7 X-ray structure cocrystallized in the $(S)$ enantiomer (Fig. 5A). Although the differences in stereochemistry preclude perfect overlap and the docking calculations employed a rigid protein, the position of the key carboxylic group that interacts with Arg 127 (see discussion below) was welloverlaid, and there was overall good correspondence in the positions of the phenyl and naphthalene rings (Fig. 5A).

Geometrically, after aligning the two FABP7 structures on their protein backbones (Ca RMSD $=0.73 \AA$, Fig. $5 C$ ), the docked $(R)$-SBFI-26 showed only minor steric clashes in the new FABP7 structure, which could be easily alleviated by local energy minimization, resulting in even better overlap (2.4 $\AA$ ). Interestingly, the reverse experiment — placing the (S)-SBFI-26 crystal into the FABP7 site that originally accommodated oleic acid — yielded some steric clashes that could not be ameliorated by a simple energy minimization, thereby explaining why the $(R)$ form was selected from the virtual screen. Thus, although there is substantial similarity between the two different FABP7 crystal structures (i.e., C-alpha RMSD $=0.73 \AA$ ), there does appear to be enough difference to preclude $(S)$-SBFI-26 from adopting the same pose without at least some conformational changes to the FABP7 structure originally containing oleic acid. Given that a rigid protein approximation was employed, this was not allowable. Notably, re-docking the $(S)$ form back into FABP7 or FABP5 from the current work yielded very low ligand RMSD values of $0.69 \AA$ and $0.88 \AA$ relative to their respective crystallographic poses.

For FABP5, however, there were greater structural differences (Fig. 5B, RMSD = $4.2 \AA$ ) between the $(R)$ predicted pose made in FABP7 and the experimental pose. These were likely due to the fact that FABP5 with (S)-SBFI-26 was not yet in an intermediate-like state, i.e., its portal region was still open relative to the closed portal in FABP7 (Ca RMSD $=2.90$ $\AA$, Fig. 5C). Rotations of $\sim 180^{\circ}$ about the cyclobutane and naphthalene ester bonds in $(S)$ SBFI-26 showed there were differences even between the two experimental geometries in 
FABP5 or FABP7 (Fig. 5A-B, green vs cyan poses). Despite these differences, the DOCK pose still showed good overlay with the FABP5 experimental pose in terms of the carboxylic acid, although the phenyl and naphthalene rings were more offset. As before, energy minimization of the docked structure in the x-ray structure (in this case FABP5) yielded a slightly better RMSD (3.8 ̊).

\section{Energetic comparison, ensemble-based geometric stability, and binding free energies for SBFI-26 with FABP7}

From an energetic perspective, the per-residue interaction footprints of SBFI-26 computed from the original prediction made in FABP7 (PDB 1FE3) yielded striking overlap with that computed using the current X-ray pose (Fig. 5). Specifically, similarly favorable van der Waals (VDW) energies (Fig. 6A) included, among others, those at positions Phe17, Met21, Pro39, Thr54, Asp77, and Arg127, and the good geometric overlap noted above for the carboxylic acid of SBFI-26 yielded nearly identical electrostatic (ES) footprints patterns (Fig. 6B), in particular the strong peaks at positions Arg107 and Arg127. Given the differences in stereochemistry and the fact that the calculations were performed using two different crystal structures, such good correspondence is notable.

To further characterize the SBFI-26 binding poses with FABP7, we employed all-atom molecular dynamics (MD) simulations to assess geometric stability and estimate free energies of binding (MM-GBSA method) using protocols recently reported to target botulinum neurotoxin serotype $\mathrm{E}^{34}$. As highlighted in Fig. 7A, which shows 100 evenly spaced snapshots taken over the course of 20-ns MD simulations, both enantiomers preserved their initial starting geometries. Interestingly, the simulation of $(S)$-SBFI-26 starting from the x-ray pose showed larger up-and-down movement at one phenyl group position, as well as left-to-right movement at the naphthalene position (Fig. 7A left). This observation is consistent with the FABP7 binding site having sufficient wiggle room to accommodate both enantiomers, as illustrated by an overlay of the MD snapshot ensembles (Fig. 7A, right). This could be advantageous when designing new analogs. Quantitatively, the MD simulations yielded very similar and stable free energies of binding (Fig. 7B). Accompanying ligand RMSD values were similarly stable, with the x-ray pose (green) yielding slightly lower values than the DOCK pose (orange). Taken together, the X-ray, docking, footprint-similarity, and MD-simulation results strongly suggest that both the $S$ and $R$ forms of SBFI-26 are geometrically and energetically compatible with the FABP7 binding site.

\section{DISCUSSION}

Over the past several years, SBFI-26 and related compounds have been actively developed as potential analgesics targeting the intracellular anandamide transporters FABP5 and FABP $7{ }^{7}$. High-resolution structures of SBFI-26 in complex with these proteins would aid our medicinal chemistry efforts to design more potent inhibitors based on the SBFI-26 scaffold. In this report, we describe the co-crystal structures of SBFI-26 in complex with FABP5 and FABP7. We found that SBFI-26 has an overall similar binding profile as the native substrate fatty acids: the carboxylate — a key moiety of the inhibitor — forms a salt 
bridge and hydrogen-bond interactions just as the fatty acids do, and there are extensive hydrophobic interactions between the phenyl rings and naphthalene ring and the substrate pocket of the FABPs, similar to the hydrophobic interaction of the aliphatic chain of the fatty acid. A comparison of the binding geometry of SBFI-26 to FABP7 with the computational prediction we reported earlier showed remarkable agreement ${ }^{7,24}$. Unique to SBFI-26 are several water-mediated hydrogen bonds between the carbonyl oxygen of the inhibitor and the backbone oxygens of Gly34 and Thr37, indicating a crucial role of water molecules in SBFI-26 binding to FABPs.

An interesting finding from our structures is that with FABP5, SBFI-26 binds at a portal site as well as the canonical site in the substrate pocket. Both binding poses were captured in cocrystal structures hence are stable. However, their binding characteristics with the transporter resembles that of the binding intermediates, because the portal regions are either partially open (portal site) or wide open (canonical site), which contrasts with the portal-closed structure of FABP7 in complex with SBFI-26 or with a fatty acid. The unique binding profile of SBFI-26 in FABP5 may afford an opportunity for the development of FABP5specific inhibitors in the future.

It is currently unclear why only the $S$ form binds to both FABP5 and FABP7 in our cocrystal structures. It is possible that the crystallization process may have selectively incorporated the $S$ form complex into the crystal lattice, leaving the $R$ form in solution. Alternatively, we suggest that the $S$ form may bind to the portal site more rapidly than to the canonical site, leading to an increased local concentration of the $S$ enantiomer for binding to the canonical site. Importantly, our computational analysis showed that both the $S$ form and the $R$ form are geometrically and energetically compatible in the binding pocket of FABP7SBFI-26 complex. Future work is needed to understand and to further improve the interaction between SBFI-26 and the human anandamide transporters.

\section{Supplementary Material}

Refer to Web version on PubMed Central for supplementary material.

\section{Acknowledgments}

This work was supported by NIH (DA035923 to D.G.D., I.O., R.R., M.K. and H.L., DA035949 to M.K., and GM083669 to R.R.), and the Van Andel Research Institute (to H.L.). We thank Brian Ralph and William J. Allen for computational assistance, and the Institute for Advanced Computational Science at Stony Brook University for providing computational resources. Diffraction data for this study were collected at X6A beamline of National Synchrotron Light Source (NSLS), Brookhaven National Laboratory and the Lilly Research Laboratories Collaborative Access Team (LRL-CAT) beamline at Advanced Photon Source (APS), Argonne National Laboratory. We thank Laura Morisco, Jordi Benach, and Stephen Wasserman for help with data collection. APS was supported by the U.S. Department of Energy, Office of Science, Office of Basic Energy Sciences, under contract no. DE-AC02-06CH11357. Use of the LRL-CAT beamline at Sector 31 of the APS was provided by Eli Lilly Company, which operates the facility.

\section{References}

1. Howlett AC, Reggio PH, Childers SR, Hampson RE, Ulloa NM, Deutsch DG. Endocannabinoid tone versus constitutive activity of cannabinoid receptors. British journal of pharmacology. 2011; 163:1329-1343. [PubMed: 21545414] 
2. Cravatt BF, Demarest K, Patricelli MP, Bracey MH, Giang DK, Martin BR, Lichtman AH. Supersensitivity to anandamide and enhanced endogenous cannabinoid signaling in mice lacking fatty acid amide hydrolase. Proc Natl Acad Sci U S A. 2001; 98:9371-9376. [PubMed: 11470906]

3. Elmes MW, Kaczocha M, Berger WT, Leung K, Ralph BP, Wang L, Sweeney JM, Miyauchi JT, Tsirka SE, Ojima I, Deutsch DG. Fatty acid-binding proteins (FABPs) are intracellular carriers for Delta9-tetrahydrocannabinol (THC) and cannabidiol (CBD). The Journal of biological chemistry. 2015; 290:8711-8721. [PubMed: 25666611]

4. Kaczocha M, Glaser ST, Deutsch DG. Identification of intracellular carriers for the endocannabinoid anandamide. Proc Natl Acad Sci U S A. 2009; 106:6375-6380. [PubMed: 19307565]

5. Sanson B, Wang T, Sun J, Wang L, Kaczocha M, Ojima I, Deutsch D, Li H. Crystallographic study of FABP5 as an intracellular endocannabinoid transporter. Acta Crystallogr D Biol Crystallogr. 2014; 70:290-298. [PubMed: 24531463]

6. Kaczocha M, Vivieca S, Sun J, Glaser ST, Deutsch DG. Fatty acid-binding proteins transport Nacylethanolamines to nuclear receptors and are targets of endocannabinoid transport inhibitors. The Journal of biological chemistry. 2012; 287:3415-3424. [PubMed: 22170058]

7. Kaczocha M, Rebecchi MJ, Ralph BP, Teng YH, Berger WT, Galbavy W, Elmes MW, Glaser ST, Wang L, Rizzo RC, Deutsch DG, Ojima I. Inhibition of fatty acid binding proteins elevates brain anandamide levels and produces analgesia. PloS one. 2014; 9:e94200. [PubMed: 24705380]

8. Yu S, Levi L, Casadesus G, Kunos G, Noy N. Fatty acid-binding protein 5 (FABP5) regulates cognitive function both by decreasing anandamide levels and by activating the nuclear receptor peroxisome proliferator-activated receptor beta/delta (PPARbeta/delta) in the brain. The Journal of biological chemistry. 2014; 289:12748-12758. [PubMed: 24644281]

9. Furuhashi M, Hotamisligil GS. Fatty acid-binding proteins: role in metabolic diseases and potential as drug targets. Nat Rev Drug Discov. 2008; 7:489-503. [PubMed: 18511927]

10. Deutsch DG. A Personal Retrospective: Elevating anandamide (AEA) by targeting fatty acid amide hydrolase (FAAH) and the fatty acid binding proteins (FABPs). Front Pharmacol. 2016; 7:370. [PubMed: 27790143]

11. Smathers RL, Petersen DR. The human fatty acid-binding protein family: evolutionary divergences and functions. Hum Genomics. 2011; 5:170-191. [PubMed: 21504868]

12. Gerstner JR, Vanderheyden WM, Shaw PJ, Landry CF, Yin JC. Fatty-acid binding proteins modulate sleep and enhance long-term memory consolidation in Drosophila. PloS one. 2011; 6:e15890. [PubMed: 21298037]

13. Shioda N, Yamamoto Y, Watanabe M, Binas B, Owada Y, Fukunaga K. Heart-type fatty acid binding protein regulates dopamine D2 receptor function in mouse brain. The Journal of neuroscience : the official journal of the Society for Neuroscience. 2010; 30:3146-3155. [PubMed: 20181611]

14. Furuhashi M, Fucho R, Gorgun CZ, Tuncman G, Cao H, Hotamisligil GS. Adipocyte/macrophage fatty acid-binding proteins contribute to metabolic deterioration through actions in both macrophages and adipocytes in mice. The Journal of clinical investigation. 2008; 118:2640-2650. [PubMed: 18551191]

15. Cao H, Gerhold K, Mayers JR, Wiest MM, Watkins SM, Hotamisligil GS. Identification of a lipokine, a lipid hormone linking adipose tissue to systemic metabolism. Cell. 2008; 134:933-944. [PubMed: 18805087]

16. Reynolds JM, Liu Q, Brittingham KC, Liu Y, Gruenthal M, Gorgun CZ, Hotamisligil GS, Stout $\mathrm{RD}$, Suttles J. Deficiency of fatty acid-binding proteins in mice confers protection from development of experimental autoimmune encephalomyelitis. Journal of immunology (Baltimore, Md. : 1950). 2007; 179:313-321.

17. Peng X, Studholme K, Kanjiya MP, Luk J, Bogdan D, Elmes MW, Carbonetti G, Tong S, Gary Teng YH, Rizzo RC, Li H, Deutsch DG, Ojima I, Rebecchi MJ, Puopolo M, Kaczocha M. Fattyacid-binding protein inhibition produces analgesic effects through peripheral and central mechanisms. Mol Pain. 2017; 13:1744806917697007. [PubMed: 28326944]

18. Sacchettini JC, Gordon JI, Banaszak LJ. Crystal structure of rat intestinal fatty-acid-binding protein. Refinement and analysis of the Escherichia coli-derived protein with bound palmitate. $\mathrm{J}$ Mol Biol. 1989; 208:327-339. [PubMed: 2671390] 
19. Scapin G, Spadon P, Mammi M, Zanotti G, Monaco HL. Crystal structure of chicken liver basic fatty acid-binding protein at 2.7 A resolution. Mol Cell Biochem. 1990; 98:95-99. [PubMed: 2266974]

20. Muller-Fahrnow A, Egner U, Jones TA, Rudel H, Spener F, Saenger W. Three-dimensional structure of fatty-acid-binding protein from bovine heart. Eur J Biochem. 1991; 199:271-276. [PubMed: 2070787]

21. Hohoff C, Borchers T, Rustow B, Spener F, van Tilbeurgh H. Expression, purification, and crystal structure determination of recombinant human epidermal-type fatty acid binding protein. Biochemistry. 1999; 38:12229-12239. [PubMed: 10493790]

22. Sacchettini JC, Gordon JI, Banaszak LJ. Refined apoprotein structure of rat intestinal fatty acid binding protein produced in Escherichia coli. Proc Natl Acad Sci U S A. 1989; 86:7736-7740. [PubMed: 2682622]

23. Storch J, McDermott L. Structural and functional analysis of fatty acid-binding proteins. J Lipid Res. 2009; 50(Suppl):S126-131. [PubMed: 19017610]

24. Berger WT, Ralph BP, Kaczocha M, Sun J, Balius TE, Rizzo RC, Haj-Dahmane S, Ojima I, Deutsch DG. Targeting fatty acid binding protein (FABP) anandamide transporters - a novel strategy for development of anti-inflammatory and anti-nociceptive drugs. PloS one. 2012; 7:e50968. [PubMed: 23236415]

25. Allen WJ, Balius TE, Mukherjee S, Brozell SR, Moustakas DT, Lang PT, Case DA, Kuntz ID, Rizzo RC. DOCK 6: Impact of new features and current docking performance. J Comput Chem. 2015; 36:1132-1156. [PubMed: 25914306]

26. Balendiran GK, Schnutgen F, Scapin G, Borchers T, Xhong N, Lim K, Godbout R, Spener F, Sacchettini JC. Crystal structure and thermodynamic analysis of human brain fatty acid-binding protein. The Journal of biological chemistry. 2000; 275:27045-27054. [PubMed: 10854433]

27. Irwin JJ, Sterling T, Mysinger MM, Bolstad ES, Coleman RG. ZINC: a free tool to discover chemistry for biology. Journal of chemical information and modeling. 2012; 52:1757-1768. [PubMed: 22587354]

28. Balius TE, Mukherjee S, Rizzo RC. Implementation and evaluation of a docking-rescoring method using molecular footprint comparisons. J Comput Chem. 2011; 32:2273-2289. [PubMed: 21541962]

29. Balius TE, Allen WJ, Mukherjee S, Rizzo RC. Grid-based molecular footprint comparison method for docking and de novo design: application to HIVgp41. J Comput Chem. 2013; 34:1226-1240. [PubMed: 23436713]

30. Emsley P, Cowtan K. Coot: model-building tools for molecular graphics. Acta Crystallogr D Biol Crystallogr. 2004; 60:2126-2132. [PubMed: 15572765]

31. Adams PD, Afonine PV, Bunkoczi G, Chen VB, Davis IW, Echols N, Headd JJ, Hung LW, Kapral GJ, Grosse-Kunstleve RW, McCoy AJ, Moriarty NW, Oeffner R, Read RJ, Richardson DC, Richardson JS, Terwilliger TC, Zwart PH. PHENIX: a comprehensive Python-based system for macromolecular structure solution. Acta Crystallogr D Biol Crystallogr. 2010; 66:213-221. [PubMed: 20124702]

32. Allen WJ, Rizzo RC. Implementation of the Hungarian algorithm to account for ligand symmetry and similarity in structure-based design. Journal of chemical information and modeling. 2014; 54:518-529. [PubMed: 24410429]

33. Pettersen EF, Goddard TD, Huang CC, Couch GS, Greenblatt DM, Meng EC, Ferrin TE. UCSF Chimera--a visualization system for exploratory research and analysis. J Comput Chem. 2004; 25:1605-1612. [PubMed: 15264254]

34. Zhou Y, McGillick BE, Teng YG, Haranahalli K, Ojima I, Swaminathan S, Rizzo RC. Identification of small molecule inhibitors of botulinum neurotoxin serotype $\mathrm{E}$ via footprint similarity. Bioorg Med Chem. 2016; 24:4875-4889. [PubMed: 27543389]

35. Case, DA., Betz, RM., Botello-Smith, W., Cerutti, DS., Cheatham, TE., III, Darden, TA., Duke, RE., Giese, TJ., Gohlke, H., Goetz, AW., Homeyer, N., Izadi, S., Janowski, P., Kaus, J., Kovalenko, A., Lee, TS., LeGrand, S., Li, P., Lin, C., Luchko, T., Luo, R., Madej, B., Mermelstein, D., Merz, KM., Monard, G., Nguyen, H., Nguyen, HT., Omelyan, I., Onufriev, A., Roe, DR., Roitberg, A., 
Sagui, C., Simmerling, CL., Swails, J., Walker, RC., Wang, J., Wolf, RM., Wu, X., Xiao, L., York, DM., Kollman, PA. AMBER 2016. University of California; San Francisco: 2016.

36. Hornak V, Abel R, Okur A, Strockbine B, Roitberg A, Simmerling C. Comparison of multiple Amber force fields and development of improved protein backbone parameters. Proteins. 2006; 65:712-725. [PubMed: 16981200]

37. Wang J, Wolf RM, Caldwell JW, Kollman PA, Case DA. Development and testing of a general amber force field. J Comput Chem. 2004; 25:1157-1174. [PubMed: 15116359]

38. Jakalian A, Jack DB, Bayly CI. Fast, efficient generation of high-quality atomic charges. AM1BCC model: II. Parameterization and validation. J Comput Chem. 2002; 23:1623-1641. [PubMed: 12395429]

39. Jorgensen WL, Chandrasekhar J, Madura JD, Impey RW, Klein ML. Comparison of simple potential functions for simulating liquid water. The Journal of chemical physics. 1983; 79:926935.

40. Srinivasan J, Miller J, Kollman PA, Case DA. Continuum solvent studies of the stability of RNA hairpin loops and helices. J Biomol Struct Dyn. 1998; 16:671-682. [PubMed: 10052623]

41. Kollman PA, Massova I, Reyes C, Kuhn B, Huo SH, Chong L, Lee M, Lee T, Duan Y, Wang W, Donini O, Cieplak P, Srinivasan J, Case DA, Cheatham TE 3rd. Calculating structures and free energies of complex molecules: Combining molecular mechanics and continuum models. Acc. Chem. Res. 2000; 33:889-897. [PubMed: 11123888]

42. Holden PM, Allen WJ, Gochin M, Rizzo RC. Strategies for lead discovery: application of footprint similarity targeting HIVgp41. Bioorg Med Chem. 2014; 22:651-661. [PubMed: 24315195]

43. Allen WJ, Yi HA, Gochin M, Jacobs A, Rizzo RC. Small molecule inhibitors of HIVgp41 Nheptad repeat trimer formation. Bioorg Med Chem Lett. 2015; 25:2853-2859. [PubMed: 26013847]

44. Armstrong EH, Goswami D, Griffin PR, Noy N, Ortlund EA. Structural basis for ligand regulation of the fatty acid-binding protein 5, peroxisome proliferator-activated receptor beta/delta (FABP5PPARbeta/delta) signaling pathway. The Journal of biological chemistry. 2014; 289:14941-14954. [PubMed: 24692551]

45. Gutierrez-Gonzalez LH, Ludwig C, Hohoff C, Rademacher M, Hanhoff T, Ruterjans H, Spener F, Lucke C. Solution structure and backbone dynamics of human epidermal-type fatty acid-binding protein (E-FABP). Biochem J. 2002; 364:725-737. [PubMed: 12049637]

46. Gillilan RE, Ayers SD, Noy N. Structural basis for activation of fatty acid-binding protein 4. J Mol Biol. 2007; 372:1246-1260. [PubMed: 17761196] 
A

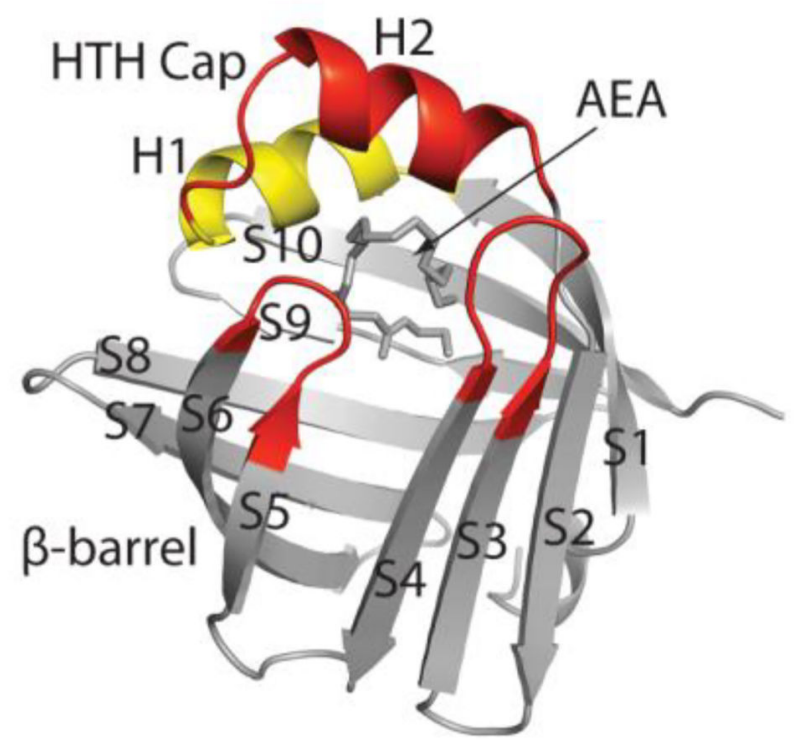

B

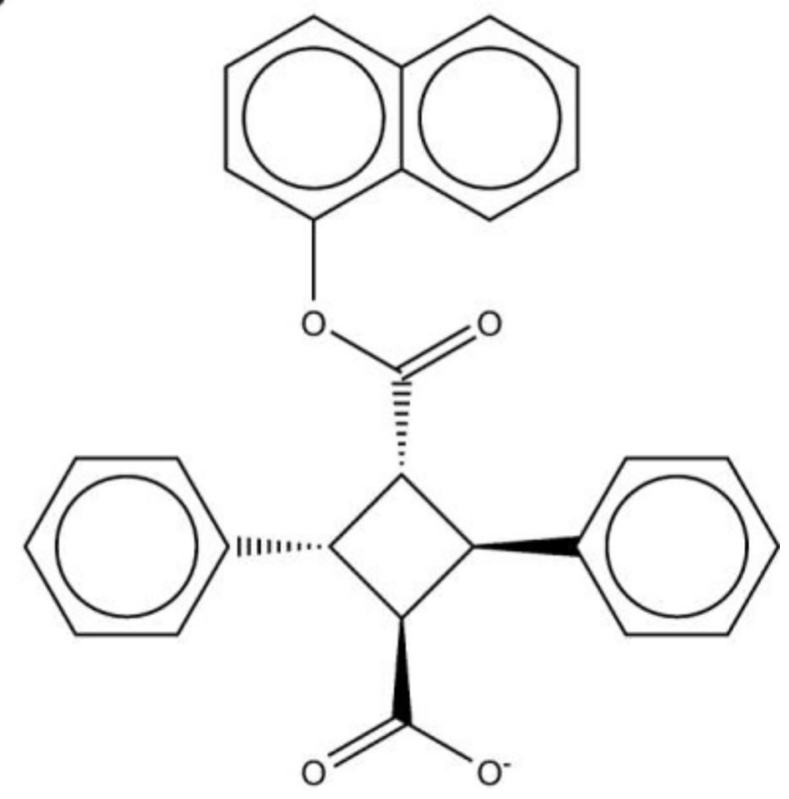

Figure 1. FABP5 is an intracellular anandamide transporter and SBFI-26 is an antinociceptive targeting FABP5

(A) Crystal structure of the mouse FABP5 in complex with the endocannabinoid anandamide (AEA) (PDB 4AZP). FABP has a $\beta$-barrel fold with a helix-turn-helix (HTH) cap. It is hypothesized that H2 of the HTH cap and the loops between S3-S4 and S5-S6 form the substrate entry port, which is highlighted in red. (B) The chemical structure of $(S)$ SBFI-26. 
A

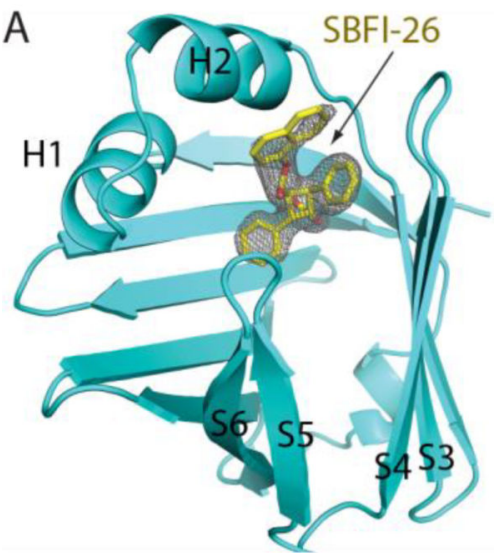

SBFI-26 at canonical site of FABP5
B

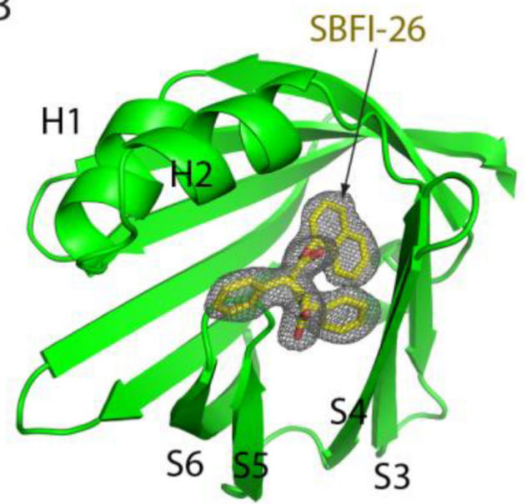

SBFI-26 at portal site of FABP5
C

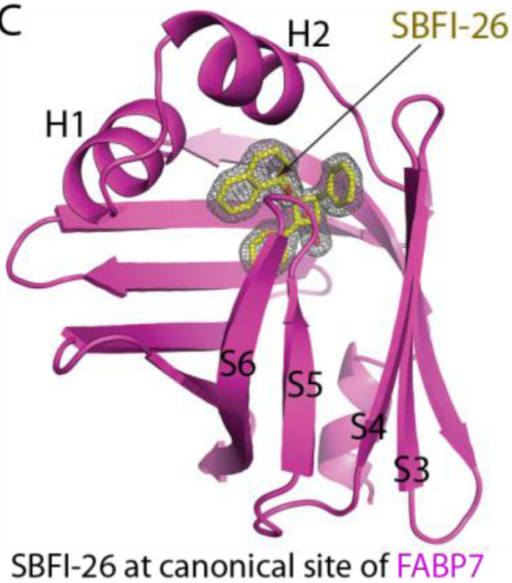

Figure 2. Overall structures of $(S)$-SBFI-26 in complex with FABP5 and FABP7

(A) SBFI-26 bound at the canonical site in human FABP5. (B) SBFI-26 bound at the portal site of the human FABP5. (C) SBFI-26 bound at the canonical site in human FABP7. In all panels, the $2 \mathrm{mF}_{\mathrm{o}}-\mathrm{DF}_{\mathrm{c}}$ electron density map of SBFI-26 is rendered at $1.0 \sigma$ and shown as grey mesh, the protein structure is shown as ribbons, and SBFI-26 is modeled in yellow stick form. 
A
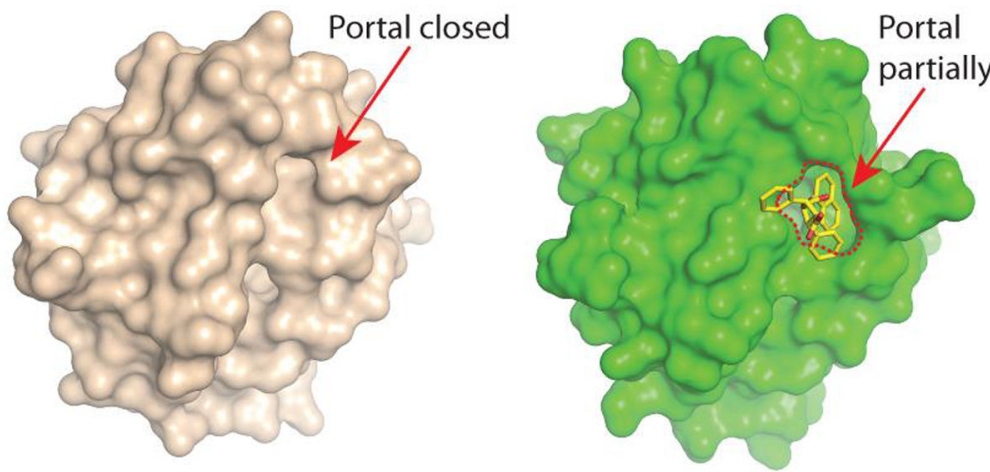

FABP5 with SBFI-26 at the portal site

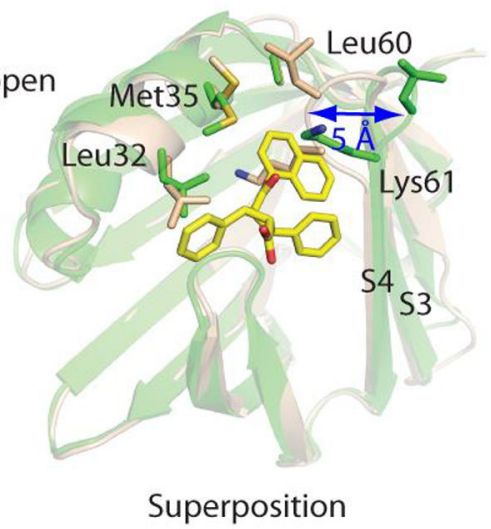

B
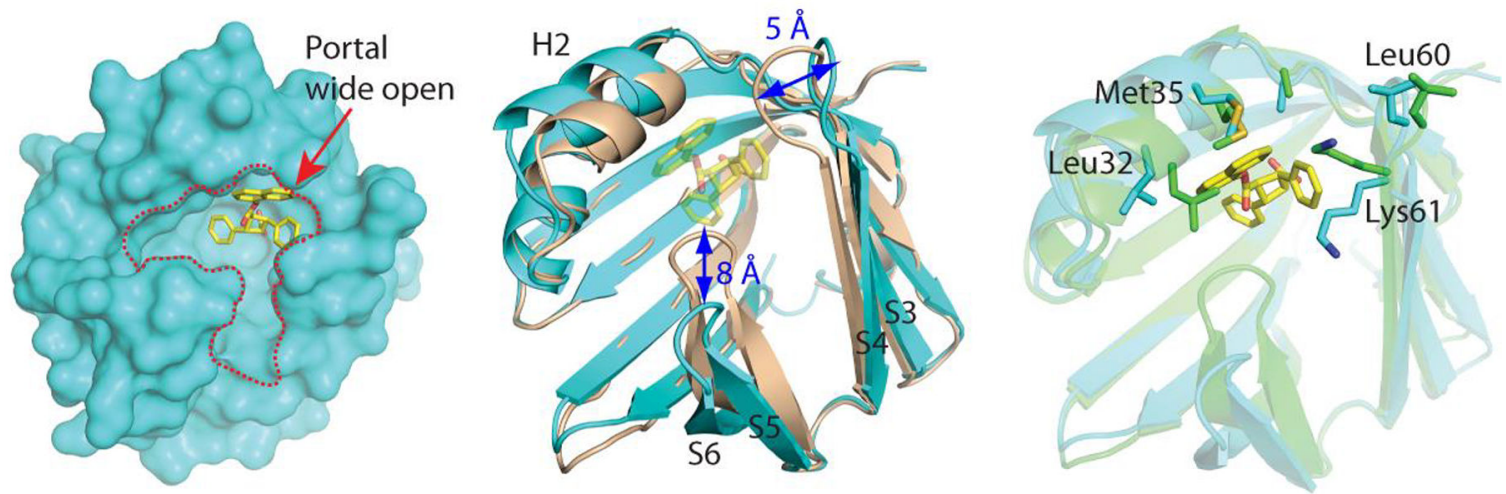

FABP5 with SBFI-26 at canonical site

Superposition with the apo form

Superposition with the portal form

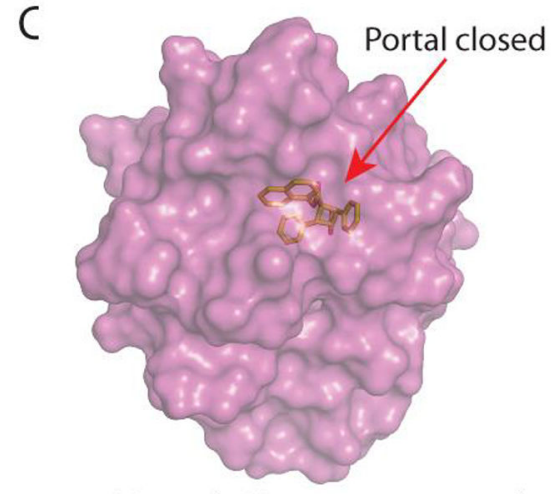

FABP7 with SBFI-26 at canonical site

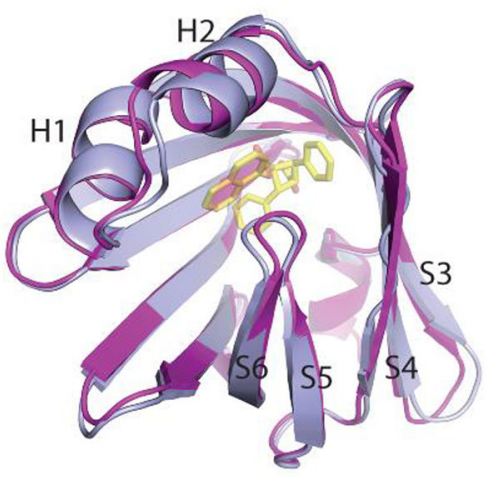

Superposition with FA-bound form

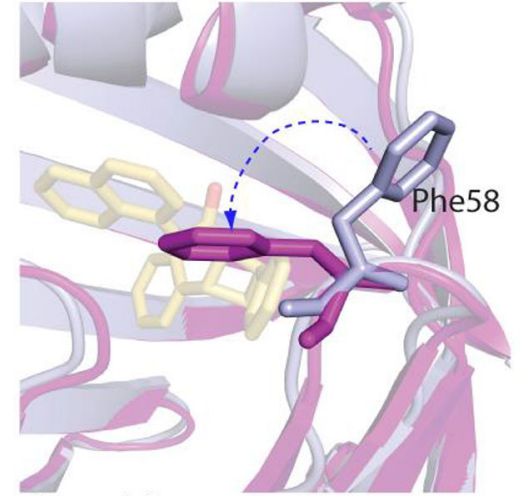

$$
\text { m }
$$

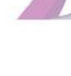

\section{Figure 3. The SBFI-26 induced conformational changes in FABP5 and FABP7}

(A) Left: The closed state of apo-FABP5 shown in surface view (PDB ID 4LKT). Only a shallow pocket is seen in the portal area (red arrow). Middle: The portal area is partially open after insertion of naphthalene group of SBFI-26. The red dashed curve marks the opened portal area. Right: Insertion of the naphthyl group in portal-site FABP5-SBFI-26 (green ribbon) disrupts the weak hydrophobic interactions found in apo-FABP5 (wheat ribbon). The helix $\mathrm{H} 2$ and the S3-S4 loop move outwards and the portal area of the portal position SBFI-26-FABP5 complex starts to open (green). The side chains of Leu60 and Lys 61 are also changed from an inward position to an outward position. (B) Left: The portal 
area is wide open in the canonical-site FABP5-SBFI-26 structure. Middle: Conformational changes in canonical site FABP5-SBFI-26 (cyan ribbon) relative to the apo-FABP (wheat ribbon). SBFI-26 is shown in yellow stick form. Right: Superposition of the portal-site (green ribbon) and the canonical site SBFI-26-FABP5 structures (cyan ribbon). Only the canonical site inhibitor is shown for clarity (yellow stick form). (C) Left: The portal area is in a closed state in FABP7-SBFI-26 structure. Middle, superposition of the fatty acid-bound FABP7 structure (light blue ribbon, PDB ID 1FDQ) and the FABP7-SBFI-26 structure (magenta ribbon). Right: The side chain of Phe58 in FABP7-SBFI-26 complex (magenta) rotates from an outside position in fatty acid-bound FABP7 (light blue) to close the portal in the FABP7-SBFI-26 structure. 
A

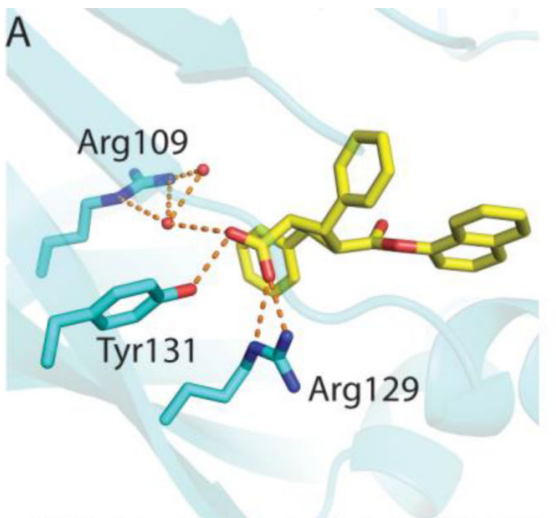

SBFI-26 at canonical site of FABP5

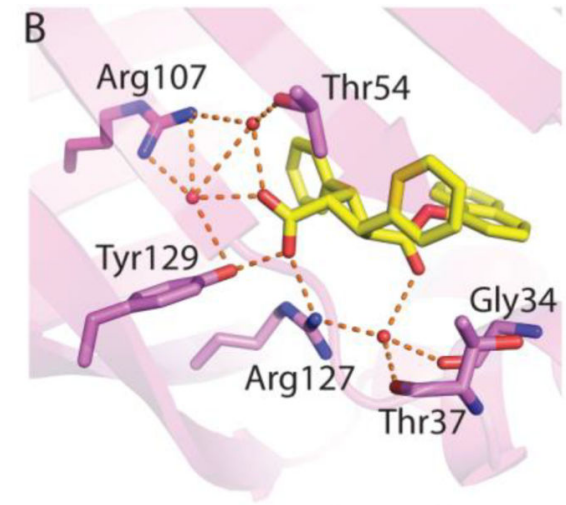

SBFI-26 at canonical site of FABP7

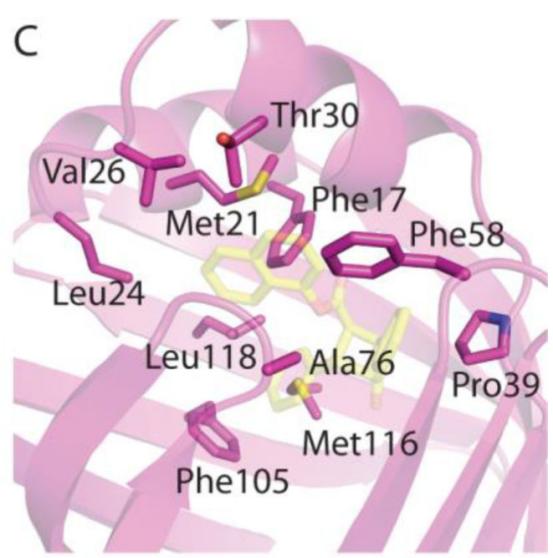

Figure 4. The binding profiles of SBFI-26 in the canonical sites of FABP5 and FABP7 (A) The FABP5-SBFI-26 canonical position (cyan). The carboxyl group of SBFI-26 forms a salt bridge with Arg129 and hydrogen bonds with Tyr131 and Arg109. Water molecules are shown as red spheres. (B) In the FABP7-SBFI-26- complex, the carboxyl group of SBFI-26 forms a salt bridge with Arg127 and hydrogen bonds with Tyr129, Arg107, and Thr54. SBFI-26 specific interactions between the carbonyl group and Gly34 and Thr37 are mediated by a water molecule. (C) Hydrophobic interactions between SBFI-26 and FABP7. 
A

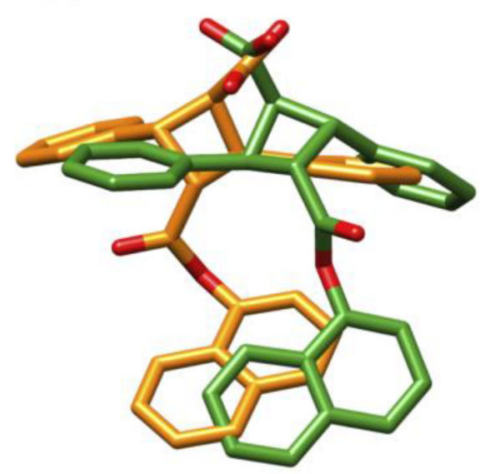

FABP7: X-ray

FABP7: DOCK (2.7 ̊̊)
B

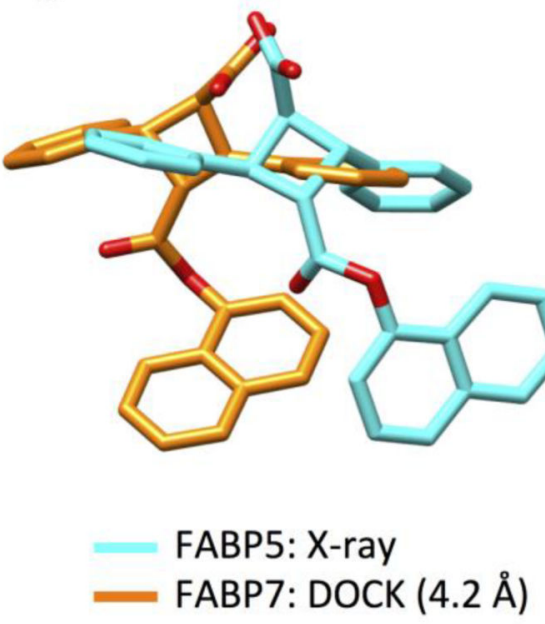

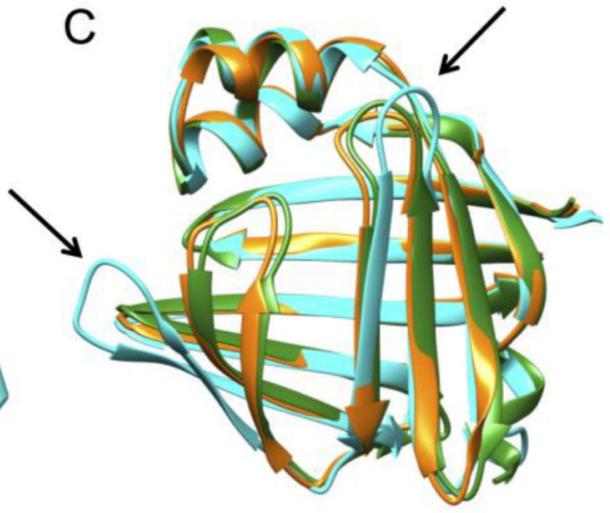

FABP7: (0.73 А) FABP5: (2.90 ̊̊) FABP7: 1FE3

Figure 5.

Comparison of the original DOCK pose in orange ${ }^{7,24}$ for $(R)$-SBFI-26 made using FABP7 with oleic acid removed (PDB 1FE3) and the current crystallographic poses of $(S)$-SBFI-26 determined with FABP7 (A) and FABP5 (B) in green and cyan, respectively. Protein residues are hidden for clarity. Overlay of the current FABP7 (green) and FABP5 (cyan) crystal structures with the previously published FABP7 (orange) structure (C). Structural comparisons made after alignment of the C-alpha backbone atoms in common. For FABP5, only the structure with a canonical site ligand is shown. 
- FABP7: X-ray - FABP7: DOCK

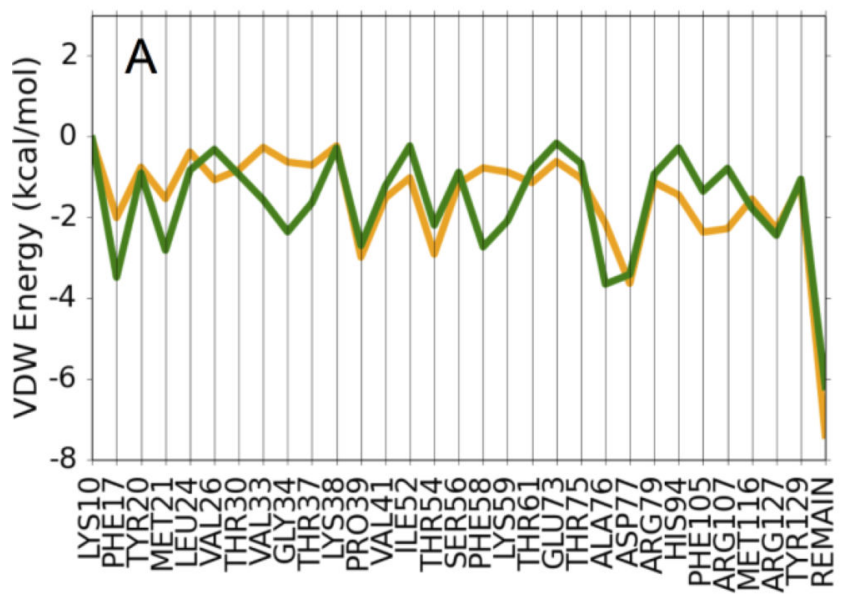

- FABP7: X-ray = FABP7: DOCK

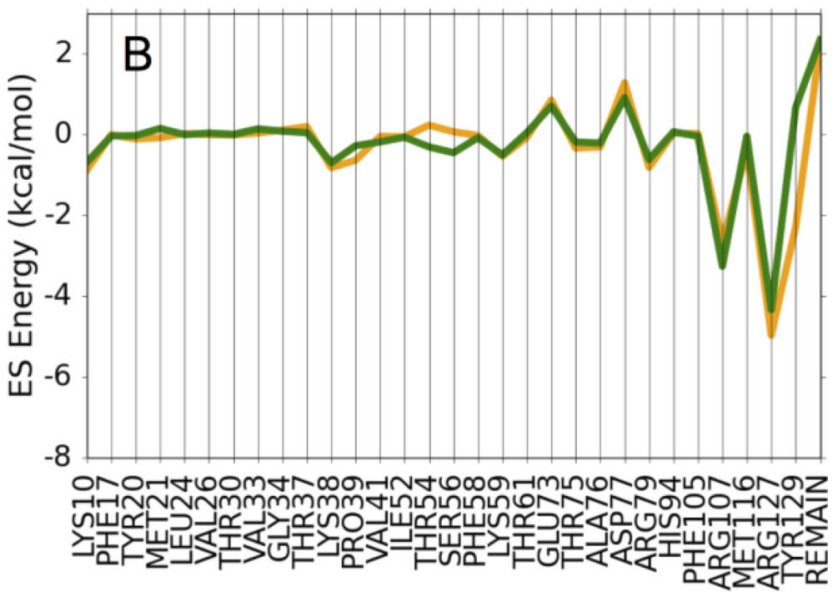

Figure 6.

Per-residue van der Waals (A) and electrostatic (B) interaction energy profiles (termed footprints) computed for SBFI-26 from the current FABP7 crystal structure (green, $S$ form) versus that from the previously reported DOCK prediction (orange, $R$ form) made using FABP7 with oleic acid removed (PDB ID 1FE3). Plots explicitly show only the top 30 protein residues based on interaction strength, with the remaining interactions summed into the residue labeled REMAIN. 


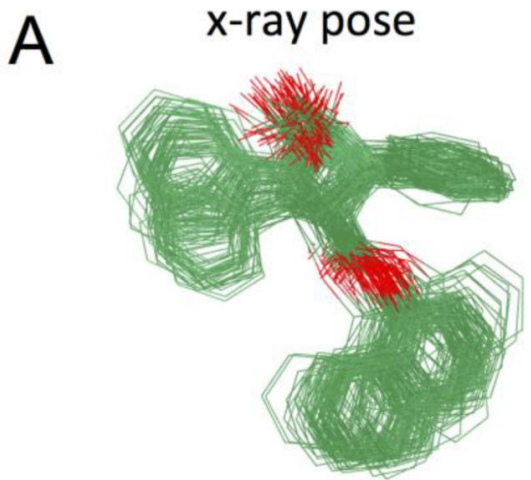

DOCK pose

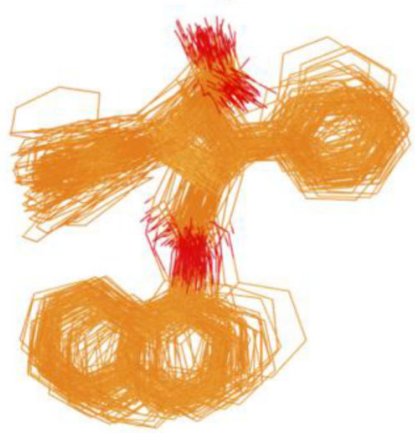

overlay

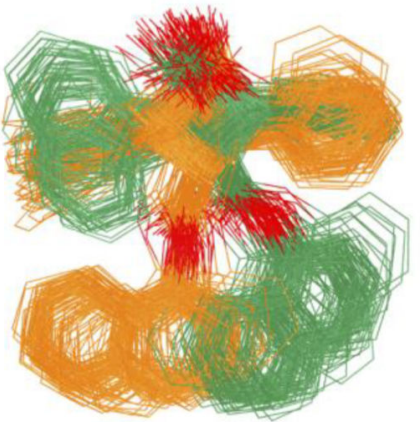

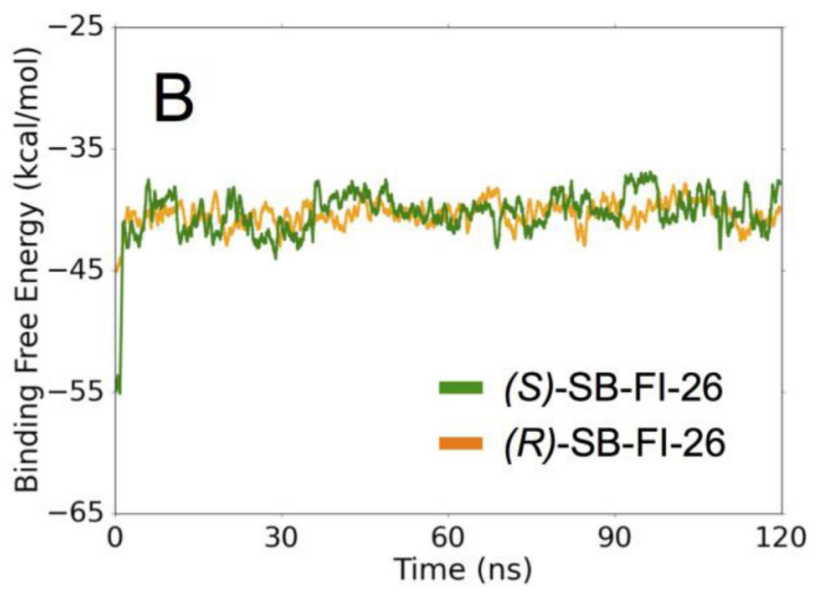

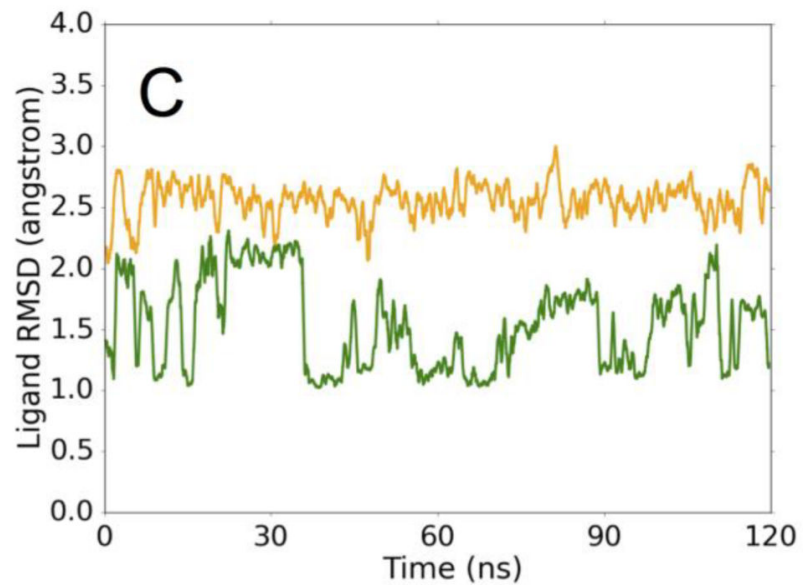

Figure 7.

(A) Molecular dynamics simulation results for $(S)$-SBFI-26 and $(R)$-SBFI-26 with FABP7 showing 100 evenly spaced ligand snapshots from 20-ns production runs. Protein residues omitted for clarity. (B) Estimated free energies of binding in kcal/mol (MM-GBSA method) plotted as running averages versus time (100-ps blocks). (C) Ligand heavy atom RMSD in angstroms plotted as running averages versus time (100-ps blocks). 


\section{Table 1}

Data collection and refinement statistics

\begin{tabular}{|c|c|c|}
\hline & FABP5-SBFI-26 & FABP7-SBFI-26 \\
\hline \multicolumn{3}{|l|}{ Data collection } \\
\hline Wavelength & 1.00000 & 0.97931 \\
\hline Space group & $\mathrm{P} 1$ & P 1211 \\
\hline \multicolumn{3}{|l|}{ Cell dimensions } \\
\hline$a, b, c(\AA)$ & $68.99,78.11,78.83$ & $53.84,73.33,70.53$ \\
\hline$a, \beta, \gamma\left({ }^{\circ}\right)$ & $61.66,69.61,78.01$ & $90,92.98,90$ \\
\hline Resolution ( $($ ) & $54.94-2.20(2.32-2.20)^{*}$ & $53.77-1.85(1.95-1.85)$ \\
\hline$R_{\text {merge }}(\%)$ & $5.6(38.6)$ & $10.7(55.1)$ \\
\hline$I / \sigma I$ & $11.2(2.3)$ & $8.0(2.3)$ \\
\hline Total reflections & 164362 & 174183 \\
\hline Completeness (\%) & $92.5(89)$ & $99.9(100)$ \\
\hline Redundancy & $2.6(2.5)$ & $3.7(3.7)$ \\
\hline \multicolumn{3}{|l|}{ Refinement } \\
\hline Resolution $(\AA)$ & $40.76-2.20$ & $53.77-1.85$ \\
\hline No. reflections & 63854 & 46755 \\
\hline$R_{\text {work }} / R_{\text {free }}$ & $0.1967 / 0.2369$ & $0.1688 / 0.1982$ \\
\hline No. of non-hydrogen atoms & 9367 & 4998 \\
\hline Protein & 8466 & 4248 \\
\hline Ligand & 557 & 168 \\
\hline Water & 344 & 582 \\
\hline$B$-factors & 41.22 & 30.60 \\
\hline Protein & 40.95 & 29.34 \\
\hline Ligand/ion & 46.48 & 44.21 \\
\hline Water & 39.19 & 35.82 \\
\hline \multicolumn{3}{|l|}{ R.m.s. deviations } \\
\hline Bond lengths $(\AA)$ & 0.008 & 0.005 \\
\hline Bond angles $\left(^{\circ}\right)$ & 0.97 & 0.73 \\
\hline \multicolumn{3}{|l|}{ Ramachandran statistics (\%) } \\
\hline Favored & 97.9 & 99 \\
\hline Allowed & 2.1 & 1 \\
\hline Outliers & 0 & 0 \\
\hline
\end{tabular}

Biochemistry. Author manuscript; available in PMC 2018 April 04. 